This is an electronic reprint of the original article. This reprint may differ from the original in pagination and typographic detail.

\author{
Author(s): Graham, Cameron M. E.; Pritchard, Taylor E.; Boyle, Paul D.; Valjus, Juuso; Tuononen, \\ Heikki; Ragogna, Paul J.
}

Title: $\quad$ Trapping Rare and Elusive Phosphinidene Chalcogenides

Year: $\quad 2017$

Version:

Please cite the original version:

Graham, C. M. E., Pritchard, T. E., Boyle, P. D., Valjus, J., Tuononen, H., \& Ragogna, P. J. (2017). Trapping Rare and Elusive Phosphinidene Chalcogenides. Angewandte Chemie International Edition, 56(1), 6236-6240.

https://doi.org/10.1002/anie.201611196

All material supplied via JYX is protected by copyright and other intellectual property rights, and duplication or sale of all or part of any of the repository collections is not permitted, except that material may be duplicated by you for your research use or educational purposes in electronic or print form. You must obtain permission for any other use. Electronic or print copies may not be offered, whether for sale or otherwise to anyone who is not an authorised user. 


\title{
Trapping Rare and Elusive Phosphinidene Chalcogenides
}

\author{
Cameron M.E. Graham, ${ }^{[a]}$ Taylor E. Pritchard, ${ }^{[a]}$ Paul D. Boyle, ${ }^{[a]}$ Juuso Valjus, ${ }^{[b]}$ Heikki M. Tuononen, ${ }^{\left[{ }^{[b]}\right]}$ \\ and Paul J. Ragogna*[a]
}

Dedicated to Prof. Risto S. Laitinen on the occasion of his $65^{\text {th }}$ birthday.

\begin{abstract}
Four-membered rings with a $\mathrm{P}_{2} \mathrm{Ch}_{2}$ core $(\mathrm{Ch}=\mathrm{S}, \mathrm{Se})$ and phosphorus in the +3 oxidation state have been synthesized. The utility of these rings as a source of monomeric phosphinidene chalcogenides was probed by the addition of an $\mathrm{N}$-heterocyclic carbene, resulting in a base-stabilized phosphinidene sulphide. Similarly, persistence of the phosphinidene selenide in solution was shown through cycloaddition chemistry with 2,3-dimethylbutadiene at elevated temperatures. The observed reactivity was explained by detailed computational work that established the conditions upon which the $\mathrm{P}_{2} \mathrm{Ch}_{2}$ rings can liberate phosphinidene chalcogenides.
\end{abstract}

Phosphinidenes (R-P (1)) are often considered the phosphorus analogues of carbenes based on their electronic structure that contains a monocoordinate, neutral $\mathrm{P}(\mathrm{I})$ centre. ${ }^{[1-9]}$ Phosphinidene chalcogenides $(\mathrm{R}-\mathrm{P}=\mathrm{Ch}(\mathbf{2} \mathrm{Ch})$ ) are oxidized versions of phosphinidenes $(\mathrm{P}(\mathrm{I}) \rightarrow \mathrm{P}(\mathrm{III}))$. Despite formally containing a lone pair of electrons at phosphorus, where one would expect an imposition of carbene-like behaviour, olefinic reactivity remains dominant. ${ }^{[10-14]}$ The presence of phosphinidene sulphides $(R-P=S)$ in solution has been verified using Diels-Alder chemistry, trapping $\mathrm{R}-\mathrm{P}=\mathrm{S}$ with dimethylbutadiene. ${ }^{[11,12,14-17]}$ Although this is elegant work demonstrating the resilience of $R-P=S$, the outcome of the reaction precludes a close examination of the $P=S$ functional group with phosphorus in the +3 oxidation state. Alternatively to cycloaddition chemistry, transition metal complexes ${ }^{[18-23]}$ and unique ligand design ${ }^{[24,25]}$ have been used to stabilize $\mathrm{R}-\mathrm{P}=\mathrm{Ch}$. With the exception of single examples demonstrating zwitterionic stabilization of $\mathrm{R}-\mathrm{P}=\mathrm{Ch}(\mathrm{Ch}=\mathrm{S}$, Se; $\mathrm{A}$, Figure 1$)$, the quest to isolate "free" phosphinidene chalcogenides remains a challenge in phosphorus-chalcogen chemistry. ${ }^{[26,27]}$ Moreover, these reports chronicle nucleophilic behaviour that stemmed from the terminal chalcogenide, ${ }^{[26,27]}$ the prevalent resonance form, rather than olefinic as one might expect for a $\mathrm{P}=\mathrm{Ch}$ functionality.

[a] Cameron M.E. Graham, Taylor E. Pritchard, Paul D. Boyle and Professor Paul J. Ragogna

Department of Chemistry and the Centre for Advanced Materials and Biomaterials Research

Western University

1151 Richmond St., London, Ontario, Canada, N6A 5B7

E-mail: pragogna@uwo.ca

[b] Juuso Valjus and Professor Heikki M. Tuononen

Department of Chemistry, NanoScience Center

University of Jyväskylä

P.O. Box 35, Fl-40014 Jyväskylä, Finland

E-mail: heikki.m.tuononen@jyu.fi

Supporting information for this article is given via a link at the end of the document.

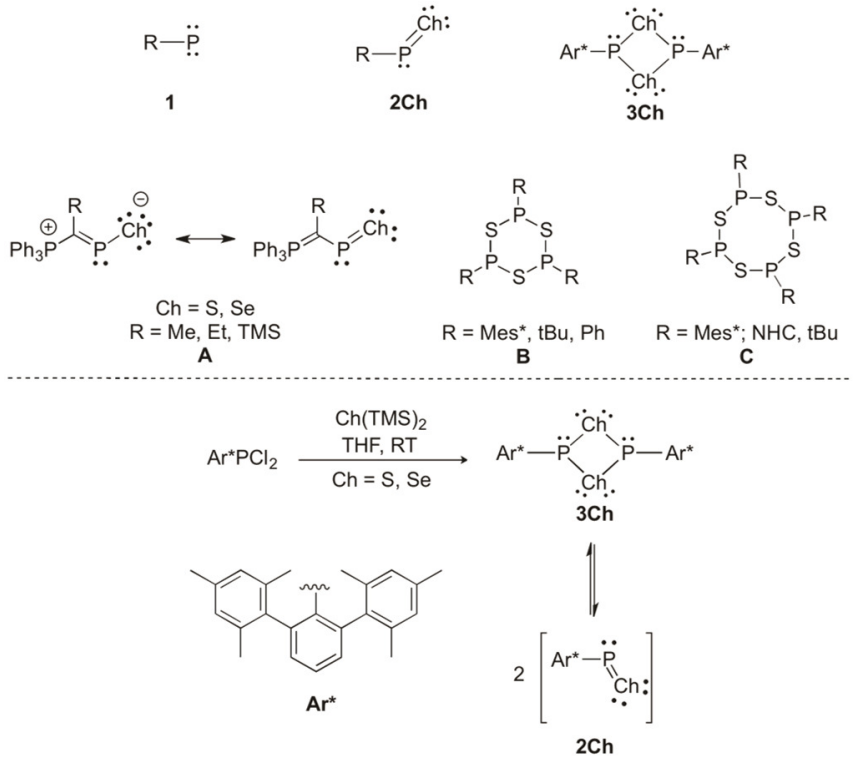

Figure 1. Top: General structures of phosphinidenes (1), phosphinidene chalcogenides $(\mathbf{2 C h})$, and $\mathrm{P}_{2} \mathrm{Ch}_{2}$ rings (3Ch). Previously reported ylidstabilized " $\mathrm{P}=\mathrm{Ch}$ " moiety $(\mathbf{A})$ and known phosphorus-chalcogen rings with a general formula $(R P S)_{n}(B, n=3 ; C, n=4)$. Bottom: General synthetic scheme for $\mathbf{3 C h}$ and their potential equilibrium with $\mathbf{2 C h}$.

The $\mathrm{R}-\mathrm{P}=\mathrm{S}$ unit is speculated as a key species in the formation of larger (RPS) $)_{n}$ rings (B and C, Figure 1), ${ }^{[28-35]}$ although the smallest member of the series (RPS) ${ }_{2}$ (3S) has yet to be identified for $\mathrm{P}(\mathrm{III})$ as compared to $\mathrm{P}(\mathrm{V})$, where numerous examples are known. ${ }^{[29,36-42]}$ Nevertheless, breaking apart the cyclic structures $(\mathrm{RPCh})_{\mathrm{n}}$ into their monomeric units (n[R-P=Ch]) is one strategy envisioned to establish systematic and stoichiometric access to a low-coordinate $\mathrm{P}$ (III) centre. In this context, we report the synthesis of (RPCh) $)_{2}$ heterocycles (3S, $\mathrm{Ch}=\mathrm{S}$; 3Se, $\mathrm{Ch}=\mathrm{Se}$ ) which represent the first four-membered organophosphorus-chalcogen rings with phosphorus in the +3 oxidation state, a species absent in the well-established chemistry of $\mathrm{P}$ and $\mathrm{S} / \mathrm{Se}$. The success in preparing the (RPS) ring provided means to the isolation of a $\mathrm{N}$-heterocyclic carbene (NHC) stabilized phosphinidene sulphide. Access to the monomeric selenide unit was ascertained by a reaction of the $(\mathrm{RPSe})_{2}$ ring with 2,3-dimethylbutadiene (dmbd), giving a sixmembered Diels-Alder product. A mechanistic investigation using density functional theory revealed that the $\mathrm{P}(\mathrm{III})$ centres in 3Ch can display Lewis acidic behaviour and react with strong nucleophiles such as NHCs, breaking the four-membered ring. The results of computational investigations also supported the notion that the reactivity of $\mathbf{3 C h}$ with dmbd involves monomeric phosphinidene chalcogenides as intermediates, consistent with the elevated temperatures required to induce reactivity. 
The 1:1 stoichiometric addition of $\mathrm{S}(\mathrm{TMS})_{2}$ (TMS = trimethylsilyl) to $\mathrm{Ar}^{*} \mathrm{PCl}_{2} \quad\left(\mathrm{Ar}^{*}=2,6-\mathrm{Mes}_{2} \mathrm{C}_{6} \mathrm{H}_{3}, \quad \mathrm{Mes}=2,4,6-\right.$ $\left(\mathrm{CH}_{3}\right)_{3} \mathrm{C}_{6} \mathrm{H}_{2}$; Figure 1) at $25^{\circ} \mathrm{C}$ resulted in the gradual appearance of a new singlet in ${ }^{31} \mathrm{P}\left\{{ }^{1} \mathrm{H}\right\} \operatorname{NMR}\left(\delta_{\mathrm{P}}=124 \mathrm{ppm}\right)$. After $16 \mathrm{~h}$, the starting material $\operatorname{Ar}^{*} \mathrm{PCl}_{2}\left(\delta_{\mathrm{P}}=160 \mathrm{ppm}\right)$ was consumed and the volatiles were removed in vacuo to give a yellow powder. Adding a small amount of $n$-pentane and placing the resulting solution at $-35^{\circ} \mathrm{C}$ for overnight gave single crystals of X-ray diffraction quality that were confirmed to be $\mathbf{3 S}$ by a subsequent structure analysis (64\% total yield). NMR spectroscopy data recorded on crystalline $3 \mathrm{~S}$ redissolved in benzene- $d_{6}$ showed the same ${ }^{31} \mathrm{P}\left\{{ }^{1} \mathrm{H}\right\}$ signal as the reaction mixture along with a single set or $\mathrm{Ar}^{*}$ resonances in the ${ }^{1} \mathrm{H}$ NMR spectrum, which confirmed the equivalence of $\mathrm{Ar}^{*} \mathrm{PS}$ fragments on the NMR time scale. In the solid state, 35 was found have a high melting point $\left(204^{\circ} \mathrm{C}\right)$, and the compound proved to be resistant to oxidation upon short exposure to the ambient environment.

An analogous synthetic procedure was used to make 3Se. In this instance, a sample of the crude reaction mixture showed the presence of multiple products as determined by ${ }^{31} \mathrm{P}\left\{{ }^{1} \mathrm{H}\right\} \mathrm{NMR}$ spectroscopy. However, the minor products could be removed by washing the crude product with $n$-pentane, yielding a single major product as evidenced by the NMR data $\left(\delta_{\mathrm{p}}=24 \mathrm{ppm},{ }^{1} \mathrm{~J}_{\mathrm{p}}\right.$ $\mathrm{se}=46 \mathrm{~Hz})$. The isolated material $(86 \%$ yield) was redissolved in $\mathrm{CH}_{2} \mathrm{Cl}_{2}$, and a sample of it was used in a $\mathrm{CH}_{2} \mathrm{Cl}_{2}$ /toluene vapour
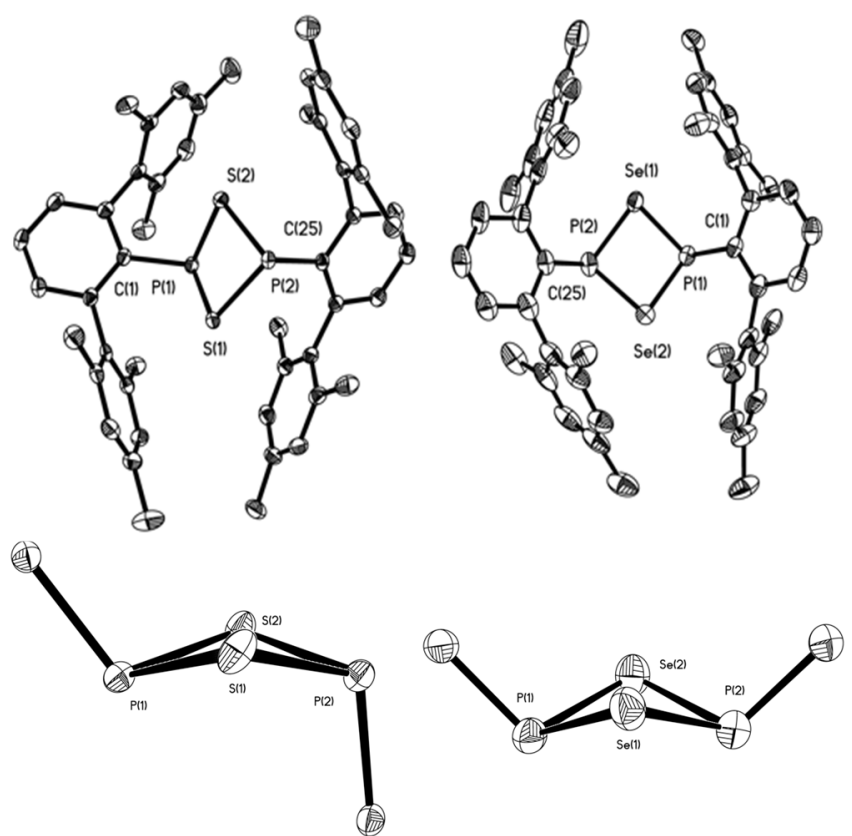

Figure 2. Solid state structures for $3 \mathrm{~S}$ (left) and 3Se (right) with thermal ellipsoids at $50 \%$ probability. Selected bond lengths $[\AA]$ and bond angles $[\%$. 3S: $\mathrm{P}(1)-\mathrm{S}(1)$ 2.1489(2), $\mathrm{P}(1)-\mathrm{S}(2)$ 2.1517(8), $\mathrm{P}(2)-\mathrm{S}(1) 2.1359(8), \mathrm{P}(2)-\mathrm{S}(2)$ 2.1479(8), $\mathrm{P}(1)-\mathrm{C}(1)$ 1.849(2), $\mathrm{P}(2)-\mathrm{C}(25)$ 1.863(2), $\mathrm{C}(1)-\mathrm{P}(1)-\mathrm{S}(1)$ 105.11(7), $\mathrm{C}(1)-\mathrm{P}(1)-\mathrm{S}(2)$ 102.97(7), S(1)-P(1)-S(2) 88.74(3), C(25)-P(2)-S(1) 110.59(7), $\mathrm{C}(25)-\mathrm{P}(2)-\mathrm{S}(2)$ 101.17(7), $\mathrm{S}(1)-\mathrm{P}(2)-\mathrm{S}(2)$ 89.18(3), $\mathrm{P}(2)-\mathrm{S}(1)-\mathrm{P}(1)$ 86.14(3), $P(2)-S(2)-P(1) \quad 85.77(3), \quad P(1)-S(1)-S(2)-P(2) \quad 34.335(4)$. 3Se: $P(1)-S e(1)$ 2.3113(14), $\quad P(1)-S e(2) \quad 2.3060(16), \quad P(2)-S e(1) \quad 2.2931(16), \quad P(2)-S e(2)$ 2.3033(16), $\quad P(1)-C(1) \quad 1.851(5), \quad P(2)-C(25) \quad 1.853(5), \quad C(1)-P(1)-S e(1)$ 103.74(15), $C(1)-P(1)-S e(2)$ 103.72(16), Se(1)-P(1)-Se(2) 88.93(6), $C(25)$ $\mathrm{P}(2)-\mathrm{Se}(1) \quad 106.10(18), \quad \mathrm{C}(25)-\mathrm{P}(2)-\mathrm{Se}(2) \quad 108.39(17), \quad \mathrm{Se}(1)-\mathrm{P}(2)-\mathrm{Se}(2)$ 89.45(6), $P(2)-S e(1)-P(1)$ 82.17(6), $P(2)-S e(2)-P(1)$ 82.06(5). $\quad P(1)-S e(1)$ $\mathrm{Se}(2)-\mathrm{P}(2)$ 45.442(8) diffusion to yield single crystals suitable for X-ray diffraction. The signal in the ${ }^{31} \mathrm{P}\left\{{ }^{1} \mathrm{H}\right\}$ NMR data of redissolved crystalline 3Se is identical to that observed in the reaction mixture; a corresponding broad triplet was also observed in the ${ }^{77} \mathrm{Se}\left\{{ }^{1} \mathrm{H}\right\}$ NMR spectrum ( $\left.\delta_{\mathrm{Se}}=484.6 \mathrm{ppm},{ }^{1} J_{\mathrm{Se}-\mathrm{P}}=45.9 \mathrm{~Hz}\right)$. Relative to 3S, 3Se is far less stable. For example, solution ${ }^{31} \mathrm{P}\left\{{ }^{1} \mathrm{H}\right\}$ NMR spectroscopy studies showed that $3 \mathrm{Se}$ decomposes when left at room temperature in solution over an extended period of time, while 3S does not show any noticeable decomposition under similar conditions.

X-ray crystallographic analysis of $\mathbf{3 S}$ showed that, in the solid state, the $\mathrm{P}_{2} \mathrm{~S}_{2}$ core adopts a butterfly conformation (Figure 2) with narrow bond angles $\left(\mathrm{P}-\mathrm{S}-\mathrm{P}_{\mathrm{avg}}=85.96(3)^{\circ}, \mathrm{S}-\mathrm{P}-\mathrm{S}_{\mathrm{avg}}=\right.$ $\left.88.96(3)^{\circ}\right)$ and $\mathrm{P}-\mathrm{S}$ bond lengths suggestive of single bonds (P$\mathrm{S}_{\mathrm{avg}}=2.1461(8) \AA$; sum of Pyykkö \& Atsumi single bond covalent radii for $P$ and $S$ is $2.14 \AA) \cdot{ }^{[43,44]}$ The solid state structure of $3 \mathrm{Se}$ is similar to $3 \mathrm{~S}$ (Figure 2) in that the $\mathrm{P}_{2} \mathrm{Se}_{2}$ core is folded with acute bond angles (P-Se- $P_{\text {avg }}=85.96(3)^{\circ}$, Se-P$\left.\mathrm{Se}_{\text {avg }}=89.20(3)^{\circ}\right)$ and $\mathrm{P}$-Se bond lengths slightly longer than that expected for single bonds $\left(\mathrm{P}-\mathrm{Se}_{\mathrm{avg}}=2.3033(16) \AA\right.$; the sum of Pyykkö \& Atsumi single bond covalent radii for $P$ and $S e$ is $2.27 \AA) .{ }^{[43,44]}$ The two structures, however, differ in the relative orientation of the terphenyl ligands i.e anti for $3 \mathbf{S}$ and syn for 3Se. The syn-conformation of $3 \mathrm{Se}$ most likely causes some ring strain and steric repulsion, leading to elongation of $\mathrm{P}$-Se bonds.

Given the acute bond angles in $\mathbf{3 C h}$, we hypothesised that the structures might be amenable to liberating $\mathbf{2} \mathbf{C h}$. To test this hypothesis, trapping reactions were carried out by dropwise addition of a THF solution of two stoichiometric equivalents of NHC (1,3-isopropyl-4,5-dimethylimidazol-2-ylidene) to a THF solution of $3 \mathrm{~S}$ at $25^{\circ} \mathrm{C}$ over $15 \mathrm{~min}$ (Figure 3 ). $\mathrm{A}{ }^{31} \mathrm{P}\left\{{ }^{1} \mathrm{H}\right\}$ NMR spectrum of the reaction mixture revealed complete consumption of $\mathbf{3 S}$ and the formation of a new product $\left(\delta_{\mathrm{P}}=29\right.$ $\mathrm{ppm}$ ). The volatiles were removed in vacuo and the crude material rinsed with $n$-pentane to give an insoluble yellow powder $\left(73 \%\right.$ yield; $\left.\delta_{\mathrm{P}}=29 \mathrm{ppm}\right)$. X-ray structural study performed on single crystals grown by $\mathrm{CH}_{2} \mathrm{Cl}_{2} / \mathrm{Et}_{2} \mathrm{O}$ vapour diffusion confirmed that the product is a base-stabilized phosphinidene sulphide (5S, Figure 4). The metrical parameters of $\mathbf{5 S}$ (Figure 4) show that the phosphorus atom is significantly pyramidal $\left(\Sigma 310.5^{\circ}\right)$ with two essentially equal P-C bonds $(1.869(4)$ and $1.853(5) \AA)$. The most notable feature in the structure is, however, the P-S bond $(2.029(14) \AA$ ) that is more than $0.1 \AA$ shorter than that in 3S, suggestive of some multiple bond character (the sum of Pyykkö \& Atsumi double bond covalent radii for $P$ and $S$ is $1.96 \AA) .{ }^{[43,44]}$

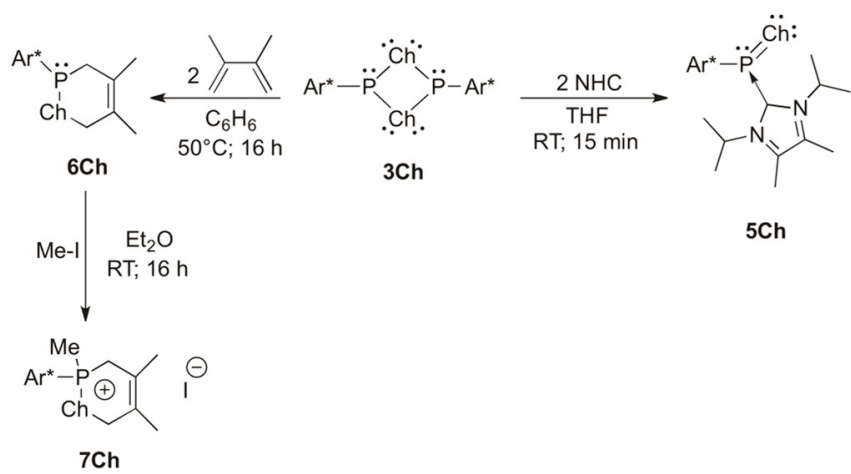

Figure 3. Trapping of $A r^{*}-P=S$ and $A r^{*}-P=S e$ by treatment of $3 S$ and $3 S$ with an $\mathrm{NHC}$ and dmbd, respectively. 


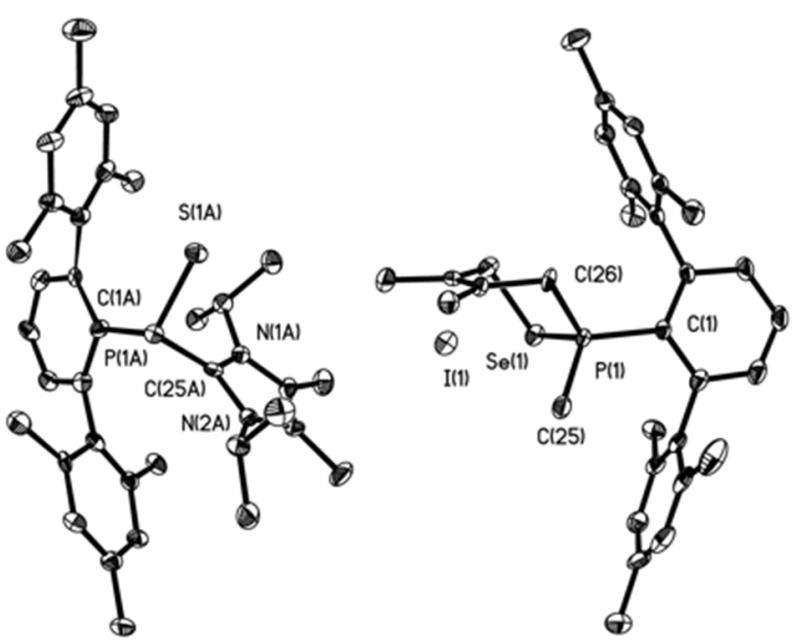

Figure 4. Solid state structures for $5 \mathrm{~S}$ (left) and 7Se (right) with thermal ellipsoids at $50 \%$ probability. Selected bond lengths $[\AA]$ and angles [ ${ }^{\circ}$. 5S: $\mathrm{P}(1)-\mathrm{C}(1)$ 1.869(4), $\mathrm{P}(1)-\mathrm{S}(1) 2.0289(14), \mathrm{P}(1)-\mathrm{C}(25)$ 1.853(5), $\mathrm{C}(1)-\mathrm{P}(1)-\mathrm{S}(1)$ 113.02(13), C(2)-C(1)-P(1) 125.5(3), C(6)-C(1)-P(1) 115.6(3), C(1)-P(1)-C(25) 98.60(19), $C(25)-P(1)-S(1)$ 98.91(13). 7Se: $P(1)-C(1)$ 1.833(5), $P(1)-S e(1)$ 2.2249(16), $P(1)-C(25)$ 1.792(6), $P(1)-C(26)$ 1.827(6), C(27)-C(28) 1.346(8), $C(1)-P(1)-S e(1)$ 111.99(18), C(2)-C(1)-P(1) 119.9(4), C(6)-C(1)-P(1) 120.4(4), $\mathrm{C}(1)-\mathrm{P}(1)-\mathrm{C}(25)$ 114.5(3), C(1)-P(1)-C(26) 115.0(3), C(25)-P(1)-Se(1) 106.3(2) $C(25)-P(1)-C(26) \quad 102.1(3), \quad P(1)-C(26)-C(27) \quad 111.0(4), \quad S e(1)-C(29)-C(28)$ $111.5(4)$

A similar base stabilization approach was undertaken to obtain 5Se. Unfortunately, this chemistry proved to be less straightforward, and a single major product could not be isolated Nevertheless, the hypothesis for accessing an as yet unknown $\mathrm{R}-\mathrm{P}=\mathrm{Se}$ fragment in solution remained, so we opted to explore the Diels-Alder chemistry known for trapping compound $2 \mathbf{S}$. However, the addition of dmbd to $3 \mathrm{Se}$ in a 2:1 stoichiometric ratio at $25^{\circ} \mathrm{C}$ showed no consumption of the starting material in ${ }^{31} \mathrm{P}\left\{{ }^{1} \mathrm{H}\right\}$ NMR spectroscopy even after two days. We therefore examined the chemistry of $3 \mathrm{Ch}$ and the possible dimer $\rightleftharpoons$ monomer equilibrium with computational methods using density functional theory at the PBE1PBE/TZVP level (see SI). For simplicity, the $A r^{*}$ groups were replaced by the parent terphenyl ligand in all calculations.

The frontier orbitals of $\mathbf{3 C h}$ revealed that the compounds are amphoteric and capable of reacting not only with Lewis acids but also with Lewis bases as the p-type atomic orbitals of phosphorus make a large contribution on both the HOMO and LUMO of $\mathbf{3 C h}$. Thus, NHCs (1,3-methylimidazol-2-ylidene) were found to add to the $P(I I I)$ centres in $\mathbf{3 S}$, leading to a stepwise breakup of the $\mathrm{P}_{2} \mathrm{~S}_{2}$ ring and the formation of $\mathbf{5 S}$ via $3 \mathrm{~S}-\mathrm{NHC}$ (Figure 5). The reaction is exergonic by $106 \mathrm{~kJ} \mathrm{~mol}^{-1}$ and has an activation energy of $42 \mathrm{~kJ} \mathrm{~mol}^{-1}$ for the second addition step. This indicates that the formation of $\mathbf{5 S}$ is spontaneous and fast even at room temperature, in agreement with experimental observations. Another possible pathway for the formation of $\mathbf{5 S}$ is the reaction between $2 \mathrm{~S}$ and $\mathrm{NHC}$, provided that $3 \mathrm{Ch}$ dissociates to $\mathbf{2} \mathrm{Ch}$ in solution. For this reason, the possible dimer $\rightleftharpoons$ monomer equilibrium was put to the fore (Figure 5). Potential energy scans revealed that the dissociation of $\mathbf{3 S}$ and $3 \mathrm{Se}$ is endergonic by 67 and $82 \mathrm{~kJ} \mathrm{~mol}^{-1}$, respectively. Furthermore, the reaction was found to proceed through a highenergy transition state with activation barriers of 113 and $147 \mathrm{~kJ}$ $\mathrm{mol}^{-1}$ for $\mathbf{3 S}$ and $\mathbf{3 S e}$, respectively. This immediately suggests that the monomer $\mathbf{2 S}$ is an unlikely intermediate en route to $\mathbf{5 S}$.

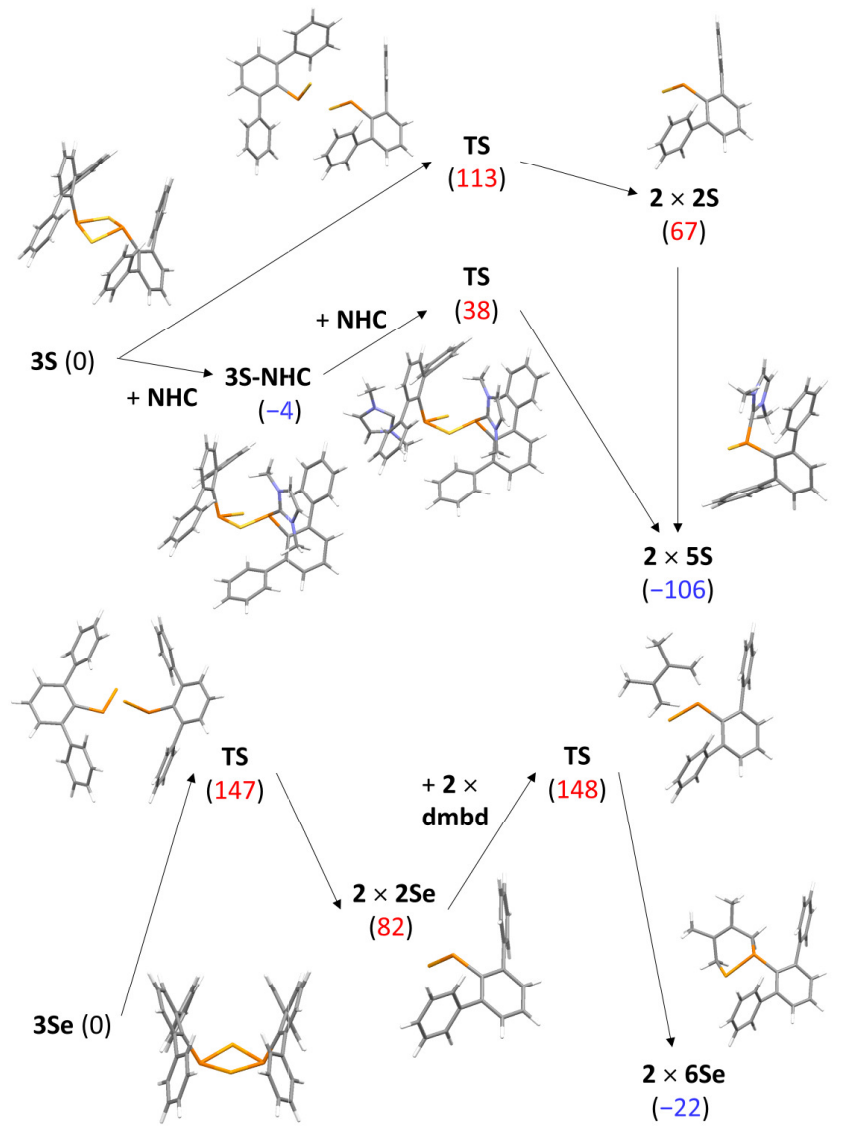

Figure 5. Reaction coordinate diagrams for the conversion of $3 S$ to $2 S / 5 S$ (top) and $3 \mathrm{Se}$ to $2 \mathrm{Se} / 6 \mathrm{Se}$ (bottom). Gibbs energies are reported in $\mathrm{kJ} \mathrm{mol}^{-1}$ and relative to $3 \mathrm{Ch}$.

As a corollary of the above, the dimers $\mathbf{3 C h}$ are the preferred end products from the reaction between $\mathrm{Ch}(\mathrm{TMS})_{2}$ and $\mathrm{Ar}^{*} \mathrm{PCl}_{2}$ even though the monomers $\mathbf{2} \mathrm{Ch}$ are most likely the species initially formed in the process.

The tendency of $\mathbf{2} \mathbf{C h}$ to dimerize follows directly from their electronic structure. As discussed in the literature, ${ }^{[11]}$ the HOMO and LUMO of $\mathbf{2} \mathrm{Ch}$ are both P-S $\pi^{*}$-orbitals. Thus, the interaction of two molecules of $\mathbf{2} \mathrm{Ch}$ allows for two pairwise donor-acceptor interactions, leading to the formation of two new P-S bonds and, consequently, $\mathbf{3 C h}$. As this process involves the occupation of the initially empty P-S antibonding LUMOs of $2 \mathrm{Ch}$, all P-S bonds in $\mathbf{3 C h}$ are single bonds. This is clearly seen in the calculated P$S$ Wiberg bond indices that are close to unity for $3 S(0.95)$ and 3Se (0.96), while those of $2 S$ (1.89) and 2Se (1.91) are significantly higher; a similar trend is also seen in the delocalization indices calculated for $2 \mathrm{Ch}$ and $3 \mathrm{Ch}$. For comparison, the Wiberg bond index for the P-S bond in $\mathbf{5 S}$ is 1.22 , which, together with the calculated natural atomic charges, indicates that the ylidic $\left(\mathrm{P}^{+}-\mathrm{S}^{-}\right)$resonance structure makes a high contribution to bonding in $\mathbf{5 S}$.

Although the calculations indicated that a dimer $\rightleftharpoons$ monomer equilibrium is unlikely at room temperature, it is plausible that some $\mathbf{2} \mathrm{Ch}$ could be liberated by heating $\mathbf{3 C h}$. It is also expected that the steric bulk of the $\mathrm{Ar}^{*}$ substituent will destabilize the dimer more than the monomer, potentially lowering the barrier for the dissociation of $\mathbf{3 C h}$ below of that predicted by our calculations. Consequently, the trapping 
reaction between $3 \mathrm{Se}$ and $\mathrm{dmbd}$ was repeated at $50^{\circ} \mathrm{C}$, which resulted in complete consumption of the starting materials after $16 \mathrm{~h}$ and the appearance of a singlet in the ${ }^{31} \mathrm{P}\left\{{ }^{1} \mathrm{H}\right\}$ spectrum $\left(\delta_{\mathrm{P}}\right.$ $\left.=11,{ }^{1} \mathrm{JSe}_{\mathrm{S}-\mathrm{P}}=184.1 \mathrm{~Hz}\right)$. The resulting compound $(6 \mathrm{Se}$, Figure 3 ) was a colourless oil, which prevented straightforward structural characterization by X-ray crystallography. For this reason, the product was derivatized using a stoichiometric amount of Me-I, targeting the quaternization of phosphorus and the formation of 7Se (Figure 3). After $16 \mathrm{~h}$ of stirring with $\mathrm{Me}-\mathrm{I}$ in $\mathrm{Et}_{2} \mathrm{O}$ at $25^{\circ} \mathrm{C}$, the starting material was fully consumed, and a new singlet appeared in the ${ }^{31} \mathrm{P}\left\{{ }^{1} \mathrm{H}\right\}$ spectrum $\left(\delta_{\mathrm{P}}=46,{ }^{1} J_{\mathrm{P}-\mathrm{Se}}=212.3 \mathrm{~Hz}\right)$. The crude white powder was washed with $n$-pentane, and the precipitate was redissolved in $\mathrm{CH}_{2} \mathrm{Cl}_{2}$ and layered with $\mathrm{Et}_{2} \mathrm{O}$ to give single crystals suitable for $\mathrm{X}$-ray diffraction (64\% total yield). The structure (Figure 4) confirmed the product to be the salt 7Se with a six-membered ring and tetrahedral geometry around the phosphorus atom. It is notable that the P-Se bond is significantly shorter in 7Se $(2.3113(15))$ than in 3Se (2.225(2) Å), indicating relief of strain upon dissociation of the dimeric structure.

The reaction between $3 \mathrm{Se}$ and dmbd was also examined computationally (Figure 5). Despite numerous attempts, we were not able to identify a Diels-Alder-type transition state (concerted or stepwise) that would connect 3Se and dmbd directly to 6Se. The lack of reactivity is not surprising considering that bonding analyses indicated that the P-Ch bonds in $\mathbf{3 C h}$ are single bonds. In contrast, $2 \mathrm{Se}$ has a $\mathrm{P}=\mathrm{Se}$ double bond and it was found to be a probable intermediate leading to $6 \mathrm{Se}$. Specifically, the DielsAlder reaction between two equivalents of $\mathbf{2 S e}$ and $\mathrm{dmbd}$ is exergonic by $104 \mathrm{~kJ} \mathrm{~mol}^{-1}$ with an activation barrier of only $66 \mathrm{~kJ}$ $\mathrm{mol}^{-1}$ (concerted mechanism). Thus, even though the conversion of $3 \mathrm{Se}$ to $2 \mathrm{Se}$ is endergonic, the facile reactivity of $2 \mathrm{Se}$ with dmbd more than compensates this and transforms the overall reaction exergonic by $22 \mathrm{~kJ} \mathrm{~mol}^{-1}$.

In conclusion, we have detailed the synthesis of fourmembered phosphorus-chalcogen rings $(\mathbf{3 C h})$ that are the first representatives of such cyclic inorganic systems with phosphorus in the +3 oxidation state. We have also demonstrated access to monomeric phosphinidenechalcogenides; the sulphur derivative being stabilized with an $\mathrm{N}$ heterocyclic carbene (5S) and the selenium congener trapped with 2,3-dimethylbutadiene (6Se). Computational work has showed that $5 \mathrm{~S}$ forms from $3 \mathrm{~S}$ via base-assisted cleavage of the $\mathrm{P}_{2} \mathrm{~S}_{2}$ ring. In contrast, the formation of $6 \mathrm{Se}$ from $3 \mathrm{Se}$ and dmbd most likely proceeds via monomeric phosphinidene selenide 2Se, a previously unknown member of the phosphinidene chalcogenide family. Further experimental and computational studies of the chemistry of $\mathbf{3 C h}$ are in progress.

\section{Acknowledgements}

The authors gratefully acknowledge the Natural Sciences and Engineering Research Council of Canada (NSERC) and the Academy of Finland (project number 282499) for financial support. We also thank CSC - The IT Center for Science in Espoo, Finland, for their support in providing computational resources.

[1] G. Fritz, T. Vaahs, H. Fleischer, E. Matern, Angew. Chem. Int. Ed. 1989, 28, 315; Angew. Chem. 1989, 101, 324

[2] F. Mathey, Angew. Chem. Int. Ed. 1987, 26, 275; Angew. Chem. 1987, 99, 285.
[3] X. Li, S. I. Weissman, T. Lin, P. P. Gaspar, J. Am. Chem. Soc. 1994, 116, 7899.

[4] A. H. Cowley, Acc. Chem. Res. 1997, 30, 445.

[5] S. Shah, M. C. Simpson, R. C. Smith, J. D. Protasiewicz, J. Am. Chem. Soc. 2001, 123, 6925.

[6] K. Lammertsma, M. J. M. Vlaar, Eur. J. Org. Chem. 2002, 1127.

[7] K. Lammertsma, Top. Curr. Chem. 2003, 237, 95.

[8] F. Mathey, Dalton Trans. 2007, 1861.

[9] H. Aktaş, J. C. Slootweg, K. Lammertsma, Angew. Chem. Int. Ed. 2010, 49, 2102; Angew. Chem. 2010, 122, 2148.

[10] P. P. Gaspar, H. Qian, A. M. Beatty, D. A. d'Avignon, J. L. F. Kao, J. C. Watt, N. P. Rath, Tetrahedron 2000, 56, 105.

[11] L. Wang, R. Ganguly, F. Mathey, Organometallics 2014, 33, 5614.

[12] C. Compain, B. Donnadieu, F. Mathey, Organometallics 2005, 24, 1762.

[13] L. D. Quin, S. Jankowski, A. G. Sommese, P. M. Lahti, J. Am. Chem. Soc. 1992, 114, 11009.

[14] S. Nakayama, M. Yoshifuji, R. Okazaki, N. Inamoto, Bull. Chem. Soc. Jpn. 1975, 48, 546.

[15] S. Nakayama, M. Yoshifuji, R. Okazaki, N. Inamoto, Chem. Commun. 1971, 1186

[16] R. Hussong, H. Heydt, M. Regitz, Z. Naturforsch. 1986, 41b, 915.

[17] P. L. Folkins, B. R. Vincent, D. N. Harpp, Tetrahedron Lett. 1991, 32, 7009.

[18] I. G. Albuerne, M. A. Alvarez, M. E. García, D. García-Vivó, M. A. Ruiz, Inorg. Chem. 2015, 54, 9810 .

[19] B. Alvarez, M. A. Alvarez, I. Amor, M. E. García, D. García-Vivõ, J. Suárez, M. A. Ruiz, Eur. J. Inorg. Chem. 2014, 1706.

[20] B. Alvarez, M. A. Alvarez, I. Amor, M. E. García, D. García-Vivó, J. Suárez, M. A. Ruiz, Inorg. Chem. 2012, 51, 7810.

[21] M. A. Alvarez, M. E. García, R. González, A. Ramos, M. A. Ruiz, Organometallics 2010, 29, 1875-1878.

[22] M. Alonso, M. A. Alvarez, M. E. García, M. A. Ruiz, H. Hamidov, J. C Jeffery, Inorg. Chem. 2010, 49, 11595.

[23] M. Alonso, M. A. Alvarez, M. E. García, D. García-Vivó, M. A. Ruiz, Inorg. Chem. 2010, 49, 8962

[24] M. Yoshifuji, M. Hirano, K. Toyota, Tetrahedron Lett. 1993, 34, 1043.

[25] M. Yoshifuji, S. Sangu, M. Hirano, K. Toyota, Chem. Lett. 1993, 1715.

[26] G. Jochem, H. Nöth, A. Schmidpeter, Angew. Chem. Int. Ed. 1993, 32, 1089; Angew. Chem. 1993, 105, 1117.

[27] G. Jochem, K. Karaghiosoff, S. Plank, S. Dick, A. Schmidpeter, Chem. Ber. 1995, 128, 1207.

[28] V. M. Baudler, D. Koch, T. Vakratsas, E. Tollis, K. Kipker, Z. Anorg. Allg Chem. 1975, 413, 239.

[29] B. Cetinkaya, P. B. Hitchcock, M. F. Lappert, A. J. Thorne, H. Goldwhite, J. Chem. Soc. Chem. Commun. 1982, 691.

[30] C. Lensch, Sheldrick, G.M. J. Chem. Soc. Dalt. Trans. 1984, 2855.

[31] C. Lensch, W. Clegg, G. M. Sheldrick, J. Chem. Soc. Dalt. Trans. 1984 723.

[32] M. Yoshifuji, K. Toyota, K. Ando, N. Inamoto, Chem. Lett. 1984, 317.

[33] K. Karaghiosoff, K. Eckstein, Phosphorus. Sulfur. Silicon Relat. Elem. 1993, 75, 257

[34] K. Kamijo, K. Toyota, M. Yoshifuji, Chem. Lett. 1999, 567.

[35] F. D. Henne, F. A. Watt, K. Schwedtmann, F. Hennersdorf, M. Kokoschka, J. J. Weigand, Chem. Commun. 2016, 52, 2023.

[36] G. He, O. Shynkaruk, M. W. Lui, E. Rivard, Chem. Rev. 2014, 114, 7815

[37] I. P. Gray, P. Bhattacharyya, A. M. Z. Slawin, J. D. Woollins, Chem. Eur. J. 2005, 11, 6221.

[38] G. Groûmann, G. Ohms, K. Karaghiosoff, Z. Anorg. Allg. Chem. 2001, 627, 1269.

[39] W. E. Van Zyl, J. P. Fackler, Phosphorus. Sulfur. Silicon Relat. Elem. 2000, 167, 117 .

[40] M. R. S. Foreman, J. Novosad, A. M. Z. Slawin, J. D. Woollins, J. Chem Soc. Dalt. Trans. 1997, 1347.

[41] M. R. S. J. Foreman, A. M. . Slawin, J. D. Woollins, J. Chem. Soc. Dalt. Trans. 1996, 3653.

[42] J. C. Fitzmaurice, D. J. Williams, P. T. Wood, J. D. Woollins, J. Chem. Soc. Chem. Commun. 1988, 741.

[43] P. Pyykkö, M. Atsumi, Chem. Eur. J. 2009, 15, 186.

[44] P. Pyykkö, M. Atsumi, Chem. Eur. J. 2009, 1512770. 